\title{
ASUHAN KEBIDANAN PADA Ny. D USIA 74 TAHUN DENGAN PROLAPSUS UTERI TING KAT II DI RUANGAN SANTA ELISABETH DI RUMAH SAKIT SANTA ELISABETH MEDAN TAHUN 2018
}

\author{
Jayanti Tafonao ${ }^{1}$, Aprilita Br. Sitepu ${ }^{2}$ \\ Prodi D3 Kebidanan STIKes Santa Elisabeth Medan
}

INTISARI

Latar Belakang : Di Indonesia sejak zaman dahulu telah lama dikenal istilah peranakan turun dan peranakan terbalik. Prolapsus uteri adalah keadaan yang sangat jarang terjadi. Frekuensi kejadian prolapsus uteri sendiri di Indonesia hanya 1,5\% saja. Kebanyakan terjadi pada usia tua dibandingkan pada usia muda. Hal ini di sebabkan oleh kelemahan dari otot dan struktur fascia pada usia yang lebih lanjut. Berdasarkan buku daftar Opname di ruangan Santa Elisabeth di Rumah Sakit Santa Elisabeth Medan Periode januari 2017- Mei 2018 sebanyak 15 rekam medis. Berdasarkan daftar Opname menunjukkan kejadian prolapsus pada usia $>70$ tahun sebanyak 5 orang dan pada usia $>30-70$ tahun 9 orang dan pada usia $<30$ tahun sebanyak 1 orang.

Tujuan : Penulis diharapkan terampil dalam memberikan asuhan kebidanan pada lansia usia 74 Tahun dengan Prolapsus Uteri tingkat II melalui pendekatan manajemen Varney.

Metode : Laporan ini merupakan laporan studi survey dengan metode Deskriptif, lokasi study kasus ini di Ruangan St. Elisabeth di Rumah Sakit Santa Elisabeth Medan. Subjek studi kasus yang di ambil penulis yaitu Lansia yang dilakukan pada 09 Maret sampai 14 Maret 2018. Teknik pengumpulan data melalui pengumpulan data subjektif dan objektif.

Hasil : Setelah dilakukan asuhan kebidanan pada Lansia selama 5 hari, dengan cara melakukan operasi histerektomi vaginal, melakukan perawatan pasca operasi dengan baik, didapatkan hasil keadaan umum ibu baik, hasil pemeriksaan fisik dalam batas normal, ibu dapat melakukan aktivitasnya seperti semula dan masalah sebagian teratasi.

Kesimpulan : Ibu diharapkan dapat menjaga personal hygiene dengan demikian komplikasi dapat terdeteksi secara dini dan segera mendapat penanganan.

Kata Kunci : Prolapsus Uteri

\begin{abstract}
Background: since formerly, In Indonesia, it has been long known the terms prolapsesd uterus and prolapsed upside down. Prolapsed uterus is a very rare condition. The frequency of prolapsed uterus in Indonesia is only 1.5\%. Most occur at an older age than a young age. This is caused by weakness of the muscles and fascia structures at a later age. Based on the book of Opname list in Santa Elisabeth room at Santa Elisabeth Hospital Medan period from January 2017 to May 2018 as many as 15 medical records. Based on the list of Opname shows prolapsed uterus at age $>70$ years for 5 people and at age> 30-70 years for 9 people and at age <30 years for 1 person.
\end{abstract}


Goals : The writer are expected to be skilled in giving midwifery care to the elderly age of 74 years with prolapsed uterus level II through Varney management approach.

Methods: This report was a survey study report with Descriptive method, the location of this case study was at Santa Elisabeth room of Santa Elisabeth Hospital Medan. Subjects of case studies taken by the writer were the Elderly conducted on March 09 to March 14, 2018. Techniques of collecting data were through subjective and objective.data collection.

Result: After 5 days of midwifery care for the elderly, by performing vaginal hysterectomy surgery, performing postoperative care well, generally, the condition of mother is good, physical examination results in normal limits, the mother can do the activity as before and the problem is partially resolved.

Conclution : Mothers are expected to maintain personal hygiene so that complications can be early detected and immediately handled.

\section{Keywords: Prolapsed Uterus}

\section{PENDAHULUAN}

Prolapsus uteri merupakan salah satu bentuk prolapsus organ panggul dan merupakan suatu kondisi jatuh atau tergelincirnya uterus (rahim) ke dalam atau keluar melalui vagina sebagai akibat dari kegagalan ligamen dan fasia yang dalam keadaan normal menyangganya. Prolapsus organ panggul merupakan masalah kesehatan yang umum terjadi dan mengenai hingga $40 \%$ wanita yang telah melahirkan dan berusia di atas 50 tahun. Prolapsus uteri menempati urutan kedua tersering setelah cystourethrocele (bladder and urethral prolapse). (Herdianti, 2015)

Menurut penelitian WHO tentang pola formasi keluarga dan kesehatan reproduksi ditemukan kejadian prolapsus uteri lebih tinggi pada wanita yang mempunyai anak lebih dari tujuh dari pada wanita yang mempunyai satu atau dua anak. Prolapsus uteri lebih berpengaruh pada perempuan di Negara-negara berkembang yang perkawinan dan kelahiran anaknya dimulai pada usia muda dan saat fertilitasnya masih tinggi. Penelitian WHO menemukan bahwa prolapsus uteri jumlahnya jauh lebih rendah dari pada kasus-kasus yang dapat dideteksi dan pemeriksaan medik.

Peningkatan usia harapan hidup di negara-negara berkembang beberapa tahun terakhir, Para dokter khususnya ahli Obstetri dan Ginekologi diharapkan familiar dengan penyakit-penyakit yang sering dialami oleh pasien lanjut usia. Prolaps Organ Panggul merupakan salah satu penyakit yang sering dialami oleh banyak wanita dewasa sekarang. Prolaps organ panggul didefinisikan sebagai penurunan abnormal atau herniasi dari organ-organ panggul dari tempat melekat atau posisi normalnya di dalam rongga panggul. Organ-organ panggul yang dapat terlibat meliputi uterus (uterine prolaps) atau ujung vagina (apical vaginal prolaps), vagina anterior (cystocele), atau vagina posterior (rectocele).

Di Indonesia sejak zaman dahulu telah lama dikenal istilah peranakan turun dan peranakan terbalik. Prolapsus uteri adalah keadaan yang sangat jarang terjadi. Frekuensi kejadian prolapsus uteri sendiri di Indonesia hanya 1,5\% saja. Kebanyakan terjadi pada usia tua dibandingkan pada usia muda. Hal ini di sebabkan oleh 
kelemahan dari otot dan struktur fascia pada usia yang lebih lanjut.

Di Sumatera Utara khususnya di RSUP Haji Adam Malik Medan periode Januari 2012-Desember 2013 menurut penelitian Fani Fatma sebanyak 232 rekam medis dengan perincian 116 kasus dan 116 kontrol. Hasil penelitian menunjukkan kejadian prolapsus uteri terbanyak terjadi pada wanita multiparitas $(60,3 \%)$, cara persalinan pervaginam $(100 \%)$, usia $\geq 40$ tahun $(95,7 \%)$, melakukan aktivitas fisik atau pekerjaan yang berat $(82,2 \%)$, dan merupakan Suku Penduduk Asli Propinsi Sumatera Utara (70,6\%). (Fani fatma, 2015)

Berdasarkan buku daftar Opname di Ruangan Santa Elisabeth di Rumah Sakit Santa Elisabeth Medan Periode Januari 2017- Mei 2018 sebanyak 15 rekam medis. Berdasarkan daftar Opname menunjukkan kejadian prolapsus pada usia $>70$ tahun sebanyak 5 orang dan pada usia $>30-70$ tahun 9 orang dan pada usia $<30$ tahun sebanyak 1 orang.

Penyebab terjadinya prolapsus belum diketahui secara pasti. Namun, secara hipotetik disebutkan penyebab utamanya adalah persalinan pervaginam dengan bayi aterm. Studi epidemiologi menunjukkan bahwa persalinan pervaginam dan penuaan adalah dua factor risiko utama untuk pengembangan prolapsus. (Herdianti, 2015)

Prolapsus uteri merupakan salah satu masalah kesehatan reproduksi. Wanita dengan prolapsus uteri dapat mengalami masalah fisik dan psiko-sosial. Masalah atau gangguan fisik tersebut merupakan salah satu kontributor utama yang mempengaruhi rendahnya kesehatan reproduksi. Meskipun prolapsus uteri jarang menyebabkan mortalitas atau morbiditas berat, tetapi dapat mempengaruhi aktivitas sehari-hari dan kualitas hidup wanita. Wanita dengan segala usia dapat mengalami prolapsus uteri, namun prolapsus lebih sering terjadi pada wanita dengan usia lebih tua. (Herdianti, 2015)

Kenaikan angka harapan hidup di Negara berkembang pada abad ini juga menyebabkan kenaikan kebutuhan praktis kesehatan terutama untuk penyakit dan gangguan yang terjadi pada populasi usia lanjut. Prolaps organ pelvis dan inkontinensia Urin merupakan kondisi yang sering di jumpai pada wanita dewasa sekarang ini. Prolaps organ pelvis sendiri adalah penurunan tidak normal atau herniasi organ pelvis dari tempat perlengkatan atau posisi nolmalnya. (Obgine, 2016).

Wanita dengan segala usia dapat mengalami prolapsus uteri, namun prolapsus lebih sering terjadi pada wanita dengan usia lebih tua. Seiring dengan meningkatnya usia harapan hidup khususnya wanita di Indonesia yang mencapai usia 74-88 tahun pada tahun 2014 maka jumlah wanita usia lanjut akan meningkat sehingga dikhawatirkan kasus prolapsus uteri juga akan semakin bertambah. Untuk alasan tersebut, maka diperlukan upaya-upaya untuk mencegah terjadinya prolapsus uteri dan untuk meminimalisir dampak yang terjadi akibat prolapsus uteri. Salah satu upaya yang dapat dilakukan adalah dengan memprediksi atau deteksi dini faktor-faktor risiko yang berpengaruh terhadap terjadinya prolapsus uteri. Sehingga peneliti tertarik untuk melakukan penelitian.

Sesuai dengan Visi Program Studi D3 Kebidanan STIKes Santa Elisabeth Medan yaitu "Menghasilkan Tenaga Bidan yang Unggul dalam Pencegahan Kegawatdaruratan Maternal dan Neonatal Berdasarkan Daya Kasih Kristus yang Menyembuhkan Sebagai Tanda Kehadiran Allah di Indonesia Tahun 2022", maka untuk mengetahui tingkat kemampuan dan komunikasi mahasiswa setelah menempuh pendidikan selama enam semester perlu diadakan evaluasi dalam bentuk uji keterampilan di lahan praktek klinik. 
Mahasiswi diwajibkan mengikuti studi kasus dalam upaya memenuhi kompetensi dan membekali pengalaman nyata di lapangan praktek tentang pelayanan kebidanan kegawatdaruratan maternal dan neonatal di Rumah Sakit Santa Elisabeth Medan Tahun 2018.

Berdasarkan latar belakang diatas maka penulis melaksanakan Asuhan Kebidanan pada kasus Ny.D usia 74 Tahun dengan prolapsus uteri tingkat II di Ruangan Santa Elisabeth di Rumah Sakit Santa Elisabeth Medan 2018.

\section{Tujuan}

\section{a. Tujuan Umum}

Untuk memberikan asuhan kebidanan pada kasus dengan prolapsus uteri tingkat II pada Ny. D usia 74 Tahun yang di dokumentasikan melalui manajemen kebidanan dan SOAP di Rumah Sakit Santa Elisabeth Medan dengan pendekatan 7 langkah varney.

\section{b. Tujuan Khusus}

1. Mampu melaksanakan pengkajian pada kasus dengan prolapsus uteri tingkat II pada Ny. D usia 74 Tahun di Rumah Sakit Santa Elisabeth Medan Tahun 2018.

2. Mampu menginterpretasi data untuk menegakkan diagnosa pada kasus dengan prolapsus uteri tingkat II pada Ny. D usia 74 Tahun di Rumah Sakit Santa Elisabeth Medan Tahun 2018.

3. Mampu menetapkan masalah potensial dan mengantisipasi penanganan pada kasus dengan prolapsus uteri tingkat II pada Ny. D usia 74 Tahun di Rumah Sakit Santa Elisabeth Medan Tahun 2018.

4. Mampu menentukan tindakan segera jika dibutuhkan pada kasus dengan prolapsus uteri tingkat II pada Ny. D usia 74 Tahun di Rumah Sakit Santa Elisabeth Medan Tahun 2018.
5. Mampu merencanakan asuhan kebidanan pada kasus dengan prolapsus uteri tingkat II yang di berikan pada Ny. D usia 74 Tahun di Rumah Sakit Santa Elisabeth Medan Tahun 2018.

6. Mampu melaksanakan asuhan kebidanan pada kasus dengan prolapsus uteri tingkat II sesuai dengan kebutuhan pada Ny. D usia 74 Tahun di Rumah Sakit Santa Elisabeth Medan Tahun 2018.

7. Mampu melakukan evaluasi hasil asuhan kebidanan pada kasus dengan prolapsus uteri tingkat II pada Ny. D usia 74 Tahun di Rumah Sakit Santa Elisabeth Medan Tahun 2018.

\section{Manfaat}

\section{a. Manfaat Teoritis}

Untuk mengaplikasikan konsep dan teori yang sudah didapat selama mengikuti pendidikan di STIKes Santa Elisabeth Medan secara langsung di lapangan khususnya dalam memberikan asuhan kebidanan pada kasus dengan prolapsus uteri tingkat II pada Ny. D usia 74 Tahun di Rumah Sakit Santa Elisabeth Medan Tahun 2018.

\section{b. Manfaat Prakt is}

1. Institusi Program Studi D3 Kebidanan STIKes Santa Elisabeth Medan

Sebagai bahan evaluasi sejauh mana kemampuan mahasiswa menguasai asuhan kebidanan pada kasus dengan prolapsus uteri.

2. Institusi Kesehatan (Rumah Sakit Santa Elisabeth Medan)

Sebagai referensi bahan bacaan dan evaluasi bagi lahan praktek untuk meningkatkan mutu pelayanan kebidanan yang lebih baik dalam memberikan asuhan kebidanan pada kasus dengan prolapsus uteri melalui 
pendekatan manajemen asuhan kebidanan 7 langkah Helen Varney.

3. Klien

Sebagai bahan penambah wawasan atau pengetahuan klien tentang pencegahan dini pada kasus prolapsus uteri.

\section{METODE STUDI KASUS}

\section{Jenis Studi Kasus}

Menjelaskan jenis studi kasus yang digunakan adalah studi kasus dengan menggunakan metode Deskriptif yakni melihat gambaran kejadian tentang asuhan kebidanan yang dilakukan di lokasi tempat pemberian asuhan kebidanan. Studi kasus ini dilakukan pada Ny. D usia 74 Tahun dengan prolapsus uteri tingkat II dilakukan di ruangan Santa Elisabeth di Rumah Sakit Santa Elisabet Medan Tahun 2018.

\section{Tempat dan waktu studi kasus}

Jalan Haji Misbah No.7, Jati, Medan Maimun, Kota Medan, Sumatera Utara dengan terjadinya prolapsus uteri tingkat II pada Ny. D usia 74 Tahun. Pada Tanggal 09 Maret 2018, Jam : $09.53 \mathrm{Wib}$.

\section{Subjek studi kasus}

Ibu mengatakan \pm 6 bulan sudah ada keluhan yaitu ada keluar peranakan dari kemaluan, dan kemarin pada Tanggal 08 Maret 2018 Jam 09.00 Wib perdarahan dan sudah berobat ke RSE (IGD) dan sudah di beri obat dan sudah berkurang tapi masih keluar flek dari kemaluan dan ibu merasa cemas dengan keadaannya.

\section{Teknik Pengumpulan Data}

\section{Metode}

Metode yang dilakukan untuk asuhan kebidanan dalam studi kasus ini adalah format asuhan kebidanan pada $\mathrm{Ny}$. D usia 74 tahun dengan prolapsus uteri dalam manajemen 7 langkahVarney.

\section{Jenis data}

Penulisan asuhan kebidanan sesuai studi kasus Ny. D usia 74 Tahun dengan prolapsus uteri pada tanggal 09 Maret 2018, yaitu:

\section{a. Data Primer}

\section{Pemeriksaan Fisik}

Pemeriksaan fisik digunakan untuk mengetahui keadaan fisik pasien secara sistematis dengan cara :

\section{a. Inspeksi}

Inspeksi adalah pemeriksaan yang dilakukan dengan cara melihat bagian tubuh yang diperiksa melalui pengamatan. Fokus inspeksi pada bagian tubuh meliputi ukuran tubuh, warna, bentuk, posisi, simetris (Handoko, 2008). Inspeksi pada pada kasus ini dilakukan secara berurutan mulai dari kepala sampai ke kaki.

\section{b. Palpasi}

Palpasi adalah suatu teknik yang menggunakan indra peraba tangan dan jari dalam hal ini palpasi dilakukan untuk memeriksa keadaan fundus uteri dan kontraksi uterus (Nursalam, 2007). Pada kasus ini pemeriksaan palpasi meliputi nadi, payudara dan abdomen

\section{c. Auskultasi}

Auskultasi adalah pemeriksaan dengan jalan mendengarkan suara yang dihasilkan oleh tubuh dengan menggunakan stetoskop. Hal-hal yang didengarkan adalah bunyi jantung, suara nafas dan bising usus. Pada kasus Ny. D dengan prolapsus uteri tingkat II pemeriksaan auskultasi meliputi pemeriksaan tekanan darah (TD).

\section{Wawancara}

Wawancara adalah suatu metode yang digunakan untuk mengumpulkan data dimana peneliti mendapatkan keterangan atau pendirian secara lisan dari seseorang sasaran penelitian 
(Responden) atau bercakap-cakap berhadapan muka dengan orang tersebut (Face to face). Wawancara dilakukan oleh tenaga medis dengan $\mathrm{Ny}$. D usia 74 Tahun dengan prolapsus uteri tingkat II 09 Maret 2018.

\section{Observasi}

Observasi

adalah teknik pengumpulan data dengan cara mengamati subjek dan melakukan berbagai macam pemeriksaan yang berhubungan dengan kasus yang akan diambil. Observasi dapat berupa pemeriksaan umum, pemeriksaan fisik dan pemeriksaan penunjang. Observasi pada kasus Ny. D dengan memberi penjelasan pada ibu bahwa keadaan ibu harus segera di lakukan tindakan segera dan perlu dilakukan kolaborasi dengan dr.Obgyn untuk dilakukan operasi hiterestomi vaginal ,dan memberitahu pada ibu hasil pemeriksaan fisik dan memotivasi ibu serta memberikan posisi dan lingkungan yang nyaman.

\section{b. Data Sekunder}

Data sekunder ini dapat diperoleh dengan mempelajari kasus atau dokumentasi pasien serta catatan asuhan kebidanan dan studi perpustakaan. Data sekunder diperoleh dari :

\section{Studi Dokume ntasi}

Studi dokumentasi adalah sumber informasi yang berhubungan dengan dokumen, baik dokumen-dokumen resmi atau pun tidak resmi. Diantaranya biografi dan catatan harian. Pada kasus Ny. D usia 74 Tahun diambil dari catatan status pasien di Rumah Sakit Santa Elisabeth Medan Tahun 2018.

\section{Studi Kepustakaan}

Studi kepustakaan adalah bahan-bahan pustaka yang sangat penting dan menunjang latar belakang teoritis dari studi penelitian. Pada kasus ini mengambil studi kepustakaan dari buku, laporan penelitian, majalah ilmiah, jurnal dan sumber terbaru terbitan tahun 2008-2016.

\section{PEMBAHASAN}

Pada pembahasan ini peneliti akan menjelaskan tentang kesenjangan yang terjadi antara teori dan praktek yang dilakukan di Rumah Sakit Santa Elisabeth Medan dengan teori yang ada. Disini peneliti akan menjelaskan kesenjangan teori dan praktek tersebut menurut langkahlangkah dalam manajemen kebidanan menurut Varney yang meliputi tujuh langkah. pembahasan ini dimaksudkan agar dapat diambil suatu kesempatan dan pemecahan masalah dari kesenjangankesenjangan yang terjadi sehingga dapat digunakan sebagai tindak lanjut dalam penerapan asuhan kebidanan yang efektif dan efisien khususnya pada pasien Ny. D usia 74 Tahun dengan Prolapsus uteri tingkat II Tahun 2018.

\section{Pengkajian}

Bidan mengumpulkan semua informasi yang akurat dan lengkap dari semua sumber yang berkaitan dengan kondisi klien seperti hasil anamnesa, hasil pemeriksaan fisik dan hasil pemeriksaan penunjang.

Dalam teori (Sarwono, 2009) mengatakan bahwa gejala dari prolapsus adalah perasaan adanya suatu benda yang mengganjal atau menonjol di genetalia eksterna, rasa sakit di panggul dan di pinggang, sering miksi, perasaan tidak dapat di kosongkan kandung kemih seluruhnya dan pada pemeriksaan penderita penderita dengan posisi jongkok ditentukan dengan pemeriksaan 2 jari, serviks lepas dari posisi normalnya atau keluar di introitus vagina. (Sarwono, 2009) 
Dalam buku Obstetri dan Ginekologi penyebab prolapsus adalah obesitas, konstipasi, trauma melahirkan, penurunan hormone estrogen pada lansia, merokok, kebanyakan anak, partus dengan penyulit dan tekanan pada intraabdominal. (Toni, Hollingwoeht, 2014)

Berdasarkan data subjektif yang penulis peroleh pada kasus Ny. D usia 74 Tahun dengan prolapsus uteri tingkat II Ibu mengatakan 6 bulan sudah ada keluhan yaitu ada keluar peranakan dari kemaluan.

Dalam data subjektif tentang keluhan pasien tidak di temukan kesenjangan antara teori dan praktek karena keluhan ibu sesuai dengan teori.

Pada data objektif yang ditemukan pengkaji Keadaan ibu Baik, Kesadaran composmentis, Tekanan darah 130/90 $\mathrm{mmHg}$, nadi $82 \mathrm{x} / \mathrm{i}, 20 \mathrm{x} / \mathrm{I}$ dan suhu 36,2 ${ }^{\circ} \mathrm{C}, \mathrm{BB}: 42 \mathrm{~kg}$ dan $\mathrm{TB}: 155 \mathrm{~cm}$, alat genetalia tidak terdapat luka tetapi ada kemerahan dan pengeluaran berupa perdarahan, pada vulva terlihat porsio di introitus vagina. Pemeriksaan Penunjang yaitu USG Abdomen Terdapat Porsio uterus pada abdomen bagian bawah.

Dalam data Objektif hasil pemeriksaan pasien di temukan kesenjangan antara teori dan praktek dimana pada teori salah satu penyebab prolapsus uteri adalah obesitas tetapi nyatanya pada hasil pemeriksaan fisik pada bagian BB : $42 \mathrm{~kg}$.

\section{Merumuskan Diagnosa/Masalah Kebidanan}

Bidan menganalisa data dasar yang diperoleh pada langkah pertama, menginterpretasikan secara akurat dan logis, sehingga dapat merumuskan diagnose atau masalah kebidanan.

Dalam buku (Sarwono, 2009) masalah yang timbul pada ibu dengan prolapsus uteri adalah perasaan adanya suatu benda yang mengganjal atau menonjol di genetalia eksterna, rasa sakit di panggul dan di pinggang, sering miksi, perasaan tidak dapat di kosongkan kandung kemih seluruhnya dan hasil pemeriksaan dengan penderita posisi jongkok dan disuruh mengejan dan ditentukan dengan pemeriksaan jari, apakah serviks lepas dari posisi normalnya atau keluar di introitus vagina dan pada saat penderita berbaring dengan posisi litotomi ditentukan panjangnya serviks.. Maka dibutuhkan kebutuhan ibu dengan prolapsus uteri Tingkat II yaitu Operasi Histerektomi Vaginal.

Pada kasus ini diagnose kebidanan adalah Ny. D usia 74 Tahun dengan Prolapsus Uteri tingkat II. Masalah yang dialami Ny. D 74 Tahun adalah Keluar peranakan dari kemaluan, ibu merasa cemas dan sudah memiliki 4 orang anak. Kebutuhan yang diberikan pada Ny. D usia 74 tahun adalah Operasi Histerektomi vaginal.

Pada langkah ini tidak ditemukan kesenjangan antara teori dan praktek, baik dalam penegakan diagnose kebidanan, masalah maupun kebutuhan. Karena diagnosa, masalah dan kebutuhan yang telah di lakukan pengkaji sama dengan teori dalam kepustakaan.

\section{Mengantisipasi Diagnosa/Masalah Potensial}

Langkah ini merupakan langkah antisipasi, sehingga dalam melaksanakan asuhan kebidanan, bidan dituntut untuk mengantisipasi permasalahan yang akan timbul dari kondisi yang ada/sudah terjadi.

Dalam buku sarwono 2009, prolapsus uteri tingkat II yaitu di mana serviks menonjol keluar dari vagina. Masalah potensial pada prolapsus uteri tingkat II adalah Tingkat III dimana seluruh uterus keluar dari introitus 
vagina. Pada kasus ini adalah prolapsus uteri tingkat III tidak terjadi, karena diagnosis sudah ditegakkan dan telah dilakukan penanganan yang tepat dan cepat.

Dalam langkah ini tidak ditemukan kesenjangan antara teori dan praktek dalam mengidentifikasikan diagnose atau masalah potensial karena masalah potensial menurut teori dan hasil pengkajian sama.

\section{Menetapkan Kebutuhan Tindakan Segera}

Bidan mengidentifikasi perlunya tindakan segera, baik tindakan intervensi, tindakan konsultasi, kolaborasi dengan dokter atau rujukan berdasarkan kondisi klien.

Dalam buku Sarwono 2009, pada prolapsus berat dengan keluhan dan penderita dikategorikan usia lanjut dan penderita tidak ingin mempunyai anak lagidan penderita setuju dengan tindakan operasi adalah pengobatan operatif atau pembedahan seperti ventrofiksasi, operasi Manchester, histerektomi vaginal, kolpokleisi.

Dalam kasus Ny. D usia 74 Tahun dengan prolapsus berat dengan keluhan dan penderita dikategorikan usia lanjut dan penderita tidak ingin mempunyai anak lagi telah, dan setuju dengan tindakan operasi, dilakukan tindakan segera berupa pembedahan yaitu operasi histerektomi Vaginal, akan tetapi sebelum melakukan operasi hysteretomi terlebih dahulu melakukan kolaborasi dengan dokter Sp.OG.

Pada tahap ini tidak terjadi kesenjangan antara teori dan praktek dalam melakukan tindakan.

\section{Menyusun Rencana Asuhan Secara Menyeluruh}

Pada langkah ini direncanakan asuhan yang menyeluruh yang ditentukan oleh langkah-langkah seblumnya. Langkah ini termasuk penatalaksanaan terhadap masalah atau diagnose yang telah diidentifikasi atau diantisipasi yang sifatnya segera ataupun rutin.

Menurut Buku Sarwono, 2009 Rencana tindakan yang dapat dilakukan pada ibu dengan prolapsus uteri berat dan penderita lanjut usia, penderita tidak menginginkan anak lagi adalah Kolaborasi dengan dokter SpOG dalam pemberian therapy, Tindakan operasi yaitu hysterektomi vaginal.

Pada kasus Ny. D usia 74 Tahun dengan prolapsus tingkat II, tindakan yang dilakukan yaitu, beri KIE tentang penyakit yang di alaminya, berikan dukungan emosional, meminta persetujuan tindakan dengan menggunakan inform consent, kolaborasi dengan dokter Sp.OG untuk tindakan Histerektomi Vaginal, berikan therapy sesuai anjuran dokter Sp.OG sebelum operasi, kolaborasi dengan dokter anastesi, persiapan ibu untuk operasi, pemantauan keadaan ibu, lakukan operasi Hysterektomi Vaginal dan perawatan pasca operasi.

Pada perencanaan tidak terjadi kesenjangan antara teori dan praktek karena perencanaan dilakukan sesuai dengan teori yang ada.

\section{Imple mentasi}

Langkah ini merupakan pelaksanaan rencana asuhan yang menyeluruh secara efesien, efektif, dan aman. Pelaksanaannya dapat dilakukan seluruhnya oleh bidan ataupun bersama dengan klien, atau anggota tim kesehatan lainnya.

Menurut Buku Sarwono, 2009 Rencana tindakan yang dapat dilakukan pada ibu dengan prolapsus uteri berat dan penderita lanjut usia, penderita tidak menginginkan anak lagi adalah : 
Kolaborasi dengan dokter Sp.OG dalam pemberian therapy ,Tindakan operasi yaitu hysterektomi vaginal.

Pada kasus ini pelaksanaan dilakukan setelah melakukan perencanaan yang telah disusun oleh bidan yaitu memberi KIE tentang penyakit yang di alaminya, memberikan dukungan emosional, meminta persetujuan tindakan dengan menggunakan inform consent, melakukan kolaborasi dengan dokter Sp.OG untuk tindakan Histerektomi Vaginal, memberikan therapy sesuai anjuran dokter Sp.OG sebelum operasi, Melakukan kolaborasi dengan dokter anastesi, mempersiapan ibu untuk operasi, Melakukan pemantauan keadaan ibu, Melakukan operasi Histerektomi Vaginal dan perawatan pasca operasi. Pada perencanaan tidak terjadi kesenjangan antara teori dan praktek karena perencanaan dilakukan sesuai dengan teori yang ada.

Sehingga pada kasus ini tidak ditemukan adanya kesenjangan antara teori dan praktek karena pelaksanaan yang dilakukan sesuai dengan teori yang ada dan pelaksanaan dilakukan sesuai dengan rencanan yang telah dilakukan sebelumnya.

\section{Evaluasi}

Dilakukan evaluasi keefektifan dari asuhan yang sudah diberikan, meliputi pemenuhan akan bantuan apakah benarbenar telah terpenuhi sesuai dengan kebutuhan sebagaimana telah diidentifikasi di dalam diagnose dan masalah.

Setelah Memberi KIE tentang penyakit yang di alaminya, memberikan dukungan emosional, meminta persetujuan tindakan dengan menggunakan inform consent, melakukan kolaborasi dengan dokter Sp.OG untuk tindakan Hysterektomi Vaginal, memberikan therapy sesuai anjuran dokter Sp.OG sebelum operasi, melakukan kolaborasi dengan dokter anastesi, mempersiapan ibu untuk operasi, melakukan pemantauan keadaan ibu, melakukan operasi Histerektomi Vaginal dan perawatan pasca operasi. Keluarga dan ibu telah melakukan anjuran dan menyetujui tindakan maka didapatkan hasil evaluasi setelah dilakukan operasi Histerktomi vaginal dengan hasil :

- Keadaan umum : Baik

- Kesadaran: Composmentis

- TTV TD : $130 / 80 \mathrm{mmHg}$ $\mathrm{T} / \mathrm{P}: 36^{\circ} \mathrm{C} / 80 \mathrm{x} / \mathrm{i}$ $\mathrm{RR}: 22 \mathrm{x} / \mathrm{i}$

- Skala nyeri : 1

- Perdarahan : Ada

- Keadaan luka operasi : Mulai kering

Dalam kasus ini tidak ditemukan kesenjangan antara teori dan praktek di lapangan dalam evaluasi kasus tersebut. Karena hasil pengkajian dalam praktek sesuai dengan teori yang ada.

\section{KESIMPULAN}

Berdasarkan asuhan kebidanan yang telah dilakukan dan pembahasan asuhan kebidanan pada Ny. D usia 74 Tahun dengan prolapsus uteri tingkat II di Ruangan Santa Elisabeth di Rumah Sakit Santa Elisabeth Medan Tahun 2018 yang menggunakan 7 langkah varney dari pengumpulan data sampai dengan evaluasi, maka penulis dapat mengambil kesimpulan.

1. Pengkajian telah dilaksananakan dengan mengumpulkan semua data menurut lembar format yang tersedia melalaui teknik wawancara dan observasi sistemik. Data subjektif khusunya pada keluhan utama Ny. D usia 74 Tahun yaitu Ibu mengatakan \pm 6 bulan sudah ada 
keluhan yaitu ada keluar peranakan dari kemaluan, dan kemarin pada tanggal 08 maret 2018, Jam 09.00 Wib perdarahan dan sudah berobat ke RSE (IGD) dan sudah di beri obat dan sudah berkurang tapi masih keluar flek dari kemaluan dan ibu merasa cemas dengan Keadaannya, Kesadaran composmentis , Tekanann darah 130/90 mmHg, Nadi $82 \mathrm{x} / \mathrm{i}$, Pernapasan $20 x / \mathrm{i}$ dan Suhu $36,2^{\circ} \mathrm{C}, \mathrm{BB}$ : $42 \mathrm{~kg}$, TB : $155 \mathrm{~cm}$, alat genetalia tidak terdapat luka tetapi ada kemerahan dan pengeluaran berupa perdarahan, pada vulva terlihat porsio uterus di introitus vagina, dan Pemeriksaan Laboratorium

a. Hematologi Erythrocyte : 3,52

b. Hemaglobin (HB) : 10,6

c. $\mathrm{HCT}: 31,5$

d. Redcell Distribution With : 11,1

e. Plabelet (PLT) : 129

f. Eosinophil (EOS) : 0,9

g. LED : 65

h. Golongan Darah : B

Pemeriksaan Penunjang Lain

a. USG Abdomen

Terdapat porsio uterus pada abdomen bagian bawah.

b. Thorax

Diaphragmae dan Kedua Sinus Biasa

Kedua Paru-Paru Tampak Bersih

Jantung Dalam Batas Normal

2. Interpretasi data dari hasil pengkajian diperoleh diagnosa kebidanan : Ny. D usia 74 Tahun dengan Prolapsus uteri tingkat II, masalah yang terjadi adalah Ibu mengatakan \pm 6 bulan sudah ada keluhan yaitu ada keluar peranakan dari kemaluan, dan kemarin pada tanggal 08 Maret 2018, Jam 09.00 Wib, perdarahan dan sudah berobat ke RSE (IGD) dan sudah di beri obat dan sudah berkurang tapi masih keluar flek dari kemaluan dan ibu merasa cemas dengan keadaannya dan Kebutuhan yang diberikan pada Ny. D usia 74 Tahun adalah operasi Hysterektomi Vaginal.
3. Diagnosa potensial pada kasus Ny. D usia 74 Tahun yaitu prolapsus uteri tingkat III, dan prolapsus uteri tingkat III tidak terjadi karena telah dilakukan penanganan segera dengan baik pada prolapsus tingkat II.

4. Tindakan segera yang dilakukan yaitu Hysterektomi Vaginal akan tetapi sebelum melakukan tindakan tersebut melakukan kolaborasi dengan dokter Sp.OG dalam pemberian therapy.

5. Perencanaan yang diberikan pada Ny. D usia 74 Tahun dengan prolapsus uteri tingkat II antara lain mencegah prolapsus tingkat III pada penderita, yaitu beri KIE tentang penyakit yang di alaminya, berikan dukungan emosional, meminta persetujuan tindakan dengan menggunakan inform consent, kolaborasi dengan dokter Sp.OG untuk tindakan Histerektomi Vaginal, berikan therapy sesuai anjuran dokter Sp.OG sebelum operasi, kolaborasi dengan dokter anastesi, persiapan ibu untuk operasi, pemantauan keadaan ibu, lakukan operasi Hysterektomi Vaginal dan perawatan pasca operasi.

6. Pelaksanaan yang diberikan pada Ny. D usia 74 Tahun dengan prolapsus uteri tingkat II antara lain memberi KIE tentang penyakit yang di alaminya, memberikan dukungan emosional, meminta persetujuan tindakan dengan menggunakan inform consent, melakukan kolaborasi dengan dokter Sp.OG untuk tindakan Histerektomi Vaginal, memberikan therapy sesuai anjuran dokter Sp.OG sebelum operasi, Melakukan kolaborasi dengan dokter anastesi, mempersiapan ibu untuk operasi, Melakukan pemantauan keadaan ibu, Melakukan operasi Hysterektomi Vaginal dan perawatan pasca operasi.

7. Evaluasi adalah tahapan penilaian terhadap keberhasilan asuhan yang telah diberikan dalam mengatasi masalah 
pasien selama perawatan dengan hasil setelah memberi KIE tentang penyakit yang di alaminya, memberikan dukungan emosional, meminta persetujuan tindakan dengan menggunakan inform consent, melakukan kolaborasi dengan dokter Sp.OG untuk tindakan Hysterektomi Vaginal, memberikan therapy sesuai anjuran dokter Sp.OG sebelum operasi, Melakukan kolaborasi dengan dokter anastesi, mempersiapan ibu untuk operasi, Melakukan pemantauan keadaan ibu, Melakukan operasi Hysterektomi Vaginal dan perawatan pasca operasi. Keluarga dan ibu telah melakukan anjuran dan menyetujui tindakan maka didapatkan hasil evaluasi setelah dilakukan operasi Hysterktomi vaginal dengan hasil :

- Keadaan umum : Baik

- Kesadaran : Composmentis

- TTV TD : 130/80 mmHg

$\mathrm{T} / \mathrm{P}: 36^{\circ} \mathrm{C} / 80 \mathrm{x} / \mathrm{i}$

$\mathrm{RR}: 22 \mathrm{x} / \mathrm{i}$

- Skala nyeri : 1

- Perdarahan : Ada

- Keadaan luka operasi : Mulai kering

\section{SARAN}

\section{Bagi Institusi Pendidikan}

Agar lebih meningkatkankan mutu pendidikan dalam proses pembelajaran baik teori maupun praktek. Agar Mahasiswa dapat meningkatkan pengetahuan dan wawasan tentang teori-teori masalah kesehatan reproduksi.

2. Bagi Rumah Sakit Santa Elisabeth Medan

Diharapkan klinik dan petugas kesehatan lainnya dapat lebih meningkatkan pelayanan dalam menangani kasus masalah kesehatan reproduksi khusunya prolapsus uteri dalam usia lanjut, baik dari segi sarana prasarana maupun tenaga kesehatan yang ada di institusi kesehatan.

\section{Bagi Klien}

Diharapkan kepada klien untuk lebih menigkatkan kesadaran akan pentingnya kesehatan reproduksi untuk mengetahui bahayanya penyulit dan komplikasi yang terdapat selama daur kehidupan khususnya prolapsus uteri pada usia lanjut.

\section{DAFTAR PUSTAKA}

Ajinata, Alfa. 2016. Uterine Prolapsus. https: //www. scribd. Com/doc /301206498/ Uterine-Prolaps-Jan2016-Jurnal-Obsgy. Diakses pada Tanggal 17 Mei 2018.

Boyle, Maureen. 2008. Kedaruratan Dalam Persalinan. Jakarta : Buku Kedokteran EGC

Fatma, Fani. 2015. Hubungan Antara Jumlah Paritas Dengan Kejadian Prolapsus Uteri. http://repository.usu.ac.id/handle/1234 56789/43369. Diakses pada Tanggal 17 Mei 2018.

Hollingworth, Toni. 2014. Diagnosis Banding Dalam Obstetri dan Ginekologi. Jakarta : Buku Kedokteran EGC

Herdianti. 2015. Prolapsus uteri.http://ejournals1.undip.ac.id/index.php/medico. Diakses pada Tanggal 17 Mei 2018.

Lisnawati, Lilis. 2013. Asuhan Kebidanan Kegawatdaruratan Maternal Dan Neonatal. Jakarta : CV. Trans Info Media.

Prawirohardjo, Sarwono. 2009. Ilmu Kandungan. Jakarta : P.T. Bina Pustaka. 
Sofian, Amru. 2011. Sinopsis Obstetri. Jakarta : Buku Kedokteran EGC.

Suryaningdyah, Dwika. 2012. Hubungan Paritas Dengan Prolapsus Uteri. http://e-journal.akbidpurworejo.ac.id/index.php/jkk2/article/ view/48. Diakses pada Tanggal 17 Mei 2018

Syafrianto. 2014. Prolapsus Uteri http://jurnalobgin.fk.unand.ac.id/index . Diakses pada Tanggal 17 Mei 2018.

Ulfah, Maria. 2013. Kesehatan Reproduksi dan Keluarga Berencana. Jakarta : CV. Trans Info Medika

Widyastuti, Yani, dkk . 2010. Kesehatan Reproduksi. Yogyakarta : Fitramaya. 